\title{
POTENSI ANTIOKSIDAN DAN SKRINING FITOKIMIA EKSTRAK DAUN MANGROVE Rhizophora mucronata, PILANG PROBOLINGGO
}

\author{
Rarasrum Dyah Kasitowati ${ }^{a, *}$, Ade Yamindago ${ }^{a}$, dan Mila Safitri ${ }^{\text {b }}$ \\ ${ }^{\text {a}}$ Program Studi Ilmu Kelautan, FPIK, Universitas Brawijaya, Malang, Indonesia \\ ${ }^{\mathrm{b}}$ Fakultas Perikanan dan Ilmu Kelautan Universitas Brawijaya, Malang, Indonesia \\ *Corresponding author: raraskasitowati@ub.ac.id
}

\begin{abstract}
Abstrak
Tujuan dari penelitian ini adalah untuk mengevaluasi aktivitas antioksidan beserta skrining fitokimia ekstrak daun $R$. mисronata. Daun $R$. mucronata diperoleh dari Pilang, Probolinggo. Ekstraksi daun mangrove menggunakan tiga pelarut dengan polaritas berbeda (Metanol, Etil asetat, dan heksan). Aktivitas antioksidan ditentukan melalui metode Diphenyl picryhydrazil (DPPH) dalam empat konsentrasi yang berbeda $(31,25 ; 62,25 ; 125 ;$ dan 250 ppm). Hasil analisis antioksidan mangrove $R$. mucronata menunjukkan bahwa ekstrak etil asetat memiliki aktivitas antioksidan tertinggi $(160,42 \mu \mathrm{g} / \mathrm{ml})$ dibandingkan ekstrak metanol $(-117,49 \mu \mathrm{g} / \mathrm{ml})$ dan ekstrak heksan $(327,61 \mu \mathrm{g} / \mathrm{ml})$. Skrining fitokimia menunjukkan bahwa ekstrak metanol mengandung $1195 \mu \mathrm{g} / \mathrm{ml}$ flavonoid, $124,44 \mu \mathrm{g} / \mathrm{ml}$ alkaloid dan 576,64 $\mu \mathrm{g} / \mathrm{ml}$ tanin. Sedangkan etil dan ekstrak heksan mengandung alkaloid $(44,91 \mu \mathrm{g} / \mathrm{ml}$ dan $41,49 \mu \mathrm{g} / \mathrm{ml})$ dan tanin $(84,84$ $\mu \mathrm{g} / \mathrm{ml}$ dan $67,30 \mu \mathrm{g} / \mathrm{ml})$.
\end{abstract}

Kata Kunci: DPH, fitokimia, mangrove, pelarut organik

\begin{abstract}
The objective of this study was to evaluate the antioxidant activities along with phytochemical screening of R. mucronata leaf extracts. $R$. mucronata leaves were collected from Pilang, Probolinggo. The extraction of mangrove leaves used three different solvents with different polarity (Methanol, Ethyl acetate, and Hexane). The antioxidant activities were determinted by the Diphenyl picryhydrazil (DPPH) method in four different concentrations $(31,25 ; 62,25 ; 125$; and $250 \mathrm{ppm})$. The antioxidant analysis of mangrove $R$. mucronata showed that the ethyl acetate extract had the highest antioxidant activity $(160,42 \mu \mathrm{g} / \mathrm{ml})$ than the methanol $(-117,49 \mu \mathrm{g} / \mathrm{ml})$ and the hexane $(327,61 \mu \mathrm{g} / \mathrm{ml})$ extracts. The phytochemical screening showed that the methanol extract contained $1195 \mu \mathrm{g} / \mathrm{ml}$ of flavonoid, $124,44 \mu \mathrm{g} / \mathrm{ml}$ of alkaloid and $576,64 \mu \mathrm{g} / \mathrm{ml}$ of tannin. Meanwhile the ethyl and the hexane extract contained alkaloid $(44,91 \mu \mathrm{g} / \mathrm{ml}$ and $41,49 \mu \mathrm{g} / \mathrm{ml})$ and tannin $(84,84 \mu \mathrm{g} / \mathrm{ml}$ and $67,30 \mu \mathrm{g} / \mathrm{ml})$.
\end{abstract}

Keywords: DPPH, mangrove, phytochemical, organic solvent

\section{PENDAHULUAN}

Radikal bebas merupakan senyawa yang sangat reaktif dan menyebabkan penyakit degeneratif pada tubuh. Pada Tahun 2018, kematian yang disebabkan oleh penyakit degeneratif diprediksi akan meningkat hingga $20 \%$ [1]. Radikal bebas dapat bersumber dari dalam (sisa metabolisme tubuh) maupun dari luar tubuh (sinar UV, polutan, dll) [2]. Upaya untuk menangkal radikal bebas yaitu menggunakan senyawa antioksidan. Ada dua jenis antioksidan yaitu dari bahan alami dan sintetik . Antioksidan alami diperoleh dari ekstrak bahan alami, sedangkan yang sintetik berasal dari hasil sintesis kimia.

Rhizophora mucronata merupakan sumber daya hayati yang melimpah di wilayah perairan Pilang, Kota Probolinggo. Mangrove ini umum dimanfaatkan oleh masyarakat sekitar untuk diolah menjadi bahan makanan seperti kopi dan tepung. $R$. mucronata pada bidang medis berpotensi sebagai obat penyakit beri-beri dan haematoma (kulit batang); hepatitis (kulit batang, bunga, daun, akar); borok (kulit batang) [4]. Eksplorasi kandungan kimia tumbuhan mangrove khususnya pada bagian daun sangat 
diperlukan untuk menemukan potensi dan informasi baru bagi masyarakat.

Penelitian ini bertujuan untuk mengetahui potensi antioksidan dan kandungan senyawa kimia aktif yang terkandung pada ekstrak daun $R$. mucronata dengan pelarut yang berbeda.

\section{BAHAN DAN METODE}

\section{Bahan}

Sampel daun $R$. mucronata diambil dari perairan Pilang, Kota Probolinggo. Daun $R$. mucronata diambil dari pohon dengan kisaran tinggi $3 \mathrm{~m}$. Panjang dan diameter daun yang diambil sebagai sampel berkisar 8,50-16 cm dan 5-10 $\mathrm{cm}$ berwarna hijau dengan panjang ganggang daun berkisar antara 2,50-5,50 cm.

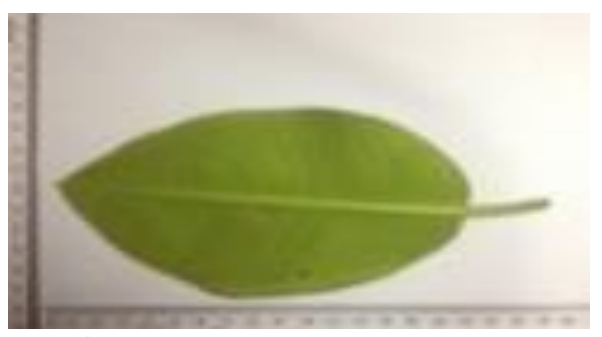

Gambar 1. Daun R. mucronata

\section{Preparasi sampel}

Sampel daun $R$. mucronata diambil kemudian dicuci bersih dengan air, lalu dilap dengan tisu hingga kering kemudian dikeringkan secara alami selama 3 hari (hingga berat kering konstan) dan dihaluskan hingga menjadi serbuk. Sampel serbuk ditimbang sebanyak $200 \mathrm{~g}$ dan diekstrasi secara bertingkat dengan menggunakan pelarut methanol, etil asetat dan n-heksan yang dilakukan selama 3 x 24 jam. Filtrat yang diperoleh kemudian dievaporasi menggunakan vacuum rotary evaporator dengan suhu $40{ }^{\circ} \mathrm{C}$ hingga diperoleh ekstrak kasar.

\section{Uji aktivitas antioksidan}

Tahapan uji aktivitas antioksidan dilakukan sebagai berikut [3]:

\section{Pembuatan larutan DPPH 0,50 mM}

Larutan DPPH disiapkan pada konsentrasi $0,50 \mathrm{mM}$, yaitu dengan menimbang 23,04 mg DPPH dan dilarutkan dengan $117 \mathrm{ml}$ metanol di dalam tube.

\section{Pembuatan larutan stok ekstrak daun R. mucronata}

Larutan stok 1000 ppm disiapkan dengan cara menimbang $50 \mathrm{mg}$ dari masing-masing ekstrak kasar, kemudian dilarutkan dengan menggunakan metanol. Volume akhir dicukupkan metanol sampai $50 \mathrm{ml}$ dalam beaker glass.

\section{Pembuatan larutan stok vitamin $\mathrm{C}$ murni}

Larutan stok 1000 ppm disiapkan dengan cara menimbang $50 \mathrm{mg}$ vitamin $\mathrm{C}$ murni dan dilarutkan dengan metanol hingga mencapai volume $50 \mathrm{ml}$ dalam beaker glass.

\section{Pengukuran aktivitas antioksidan dengan metode DPPH \\ a) Pengukuran serapan blanko DPPH}

Larutan DPPH $\quad 0,50 \mathrm{mM}$ diambil sebanyak sebanyak $1 \mathrm{ml}$ dan ditambahkan metanol hingga $5 \mathrm{ml}$ dalam cuvette. Larutan ini kemudian dihomogenkan dan diinkubasi selama 30 menit, selanjutnya serapan diukur dengan spektrofotometer UV-Vis pada panjang gelombang $517 \mathrm{~nm}$.

\section{b) Pengukuran aktivitas pengikatan radikal bebas DPPH dengan sampel}

Ekstrak mula-mula dibuat pada konsentrasi 1000 ppm, dilanjutkan untuk penentuan konsentrasi larutan uji aktivitas antioksidan pada seri konsentrasi seperempat dan selanjutnya separuh dari konsentrasi larutan induk yaitu sebesar 250; 125;62,50 dan 31,25 ppm. Masing-masing empat konsentrasi uji tersebut diambil sampel sebanyak $4 \mathrm{ml}$ kemudian ditambahkan $1 \mathrm{ml}$ larutan DPPH 0,50 mM. Langkah selanjutnya sampel diinkubasi selama 30 menit pada suhu ruang hingga terjadi perubahan warna dari aktivitas DPPH, semua sampel dibuat triplo (tiga kali pengulangan). Setelah semua sampel telah diinkubasi, ekstrak dianalisa 
menggunakan spektofotometer UV-Vis pada panjang gelombang $517 \mathrm{~nm}$.

\section{c) Pengukuran aktivitas pengikat radikal bebas DPPH sebagai larutan pembanding}

Larutan pembanding dibuat dari vitamin $\mathrm{C}$ yang dilarutkan dengan pelarut metanol masing-masing konsentrasi 2, 4, 6, dan 8 ppm dengan cara mengambil masing-masing $10 \mu \mathrm{l}$, $20 \mu \mathrm{l}, 40 \mu \mathrm{l}$, dan $80 \mu \mathrm{l}$ dari larutan stok vitamin C murni 1000 ppm pada tabung reaksi. Vitamin $\mathrm{C}$ yang digunakan adalah vitamin $C$ murni. Di mana vitamin $C$ jenis ini merupakan antioksidan yang dapat mencegah oksidasi dan merupakan nutrien serta vitamin yang larut dalam air dan penting untuk menjaga kesehatan.

Persentase pengikatan radikal bebas dapat dihitung dengan rumus :

$$
\text { T6 Inhibisi }=\frac{(\text { Abs Blanko-Abs Sampel) }}{\text { Abs Blanko }} \times 100
$$

Larutan blanko yang digunakan adalah methanol dan DPPH. Potensi antioksidan diukur dari nilai $\mathrm{IC}_{50} \quad(50 \%$ Inhibitory Concentration) yang diperoleh melalui persamaan regresi linear. Nilai $\mathrm{IC}_{50}$ merupakan konsentrasi efektif ekstrak yang dibutuhkan untuk meredam $50 \%$ dari total DPPH, sehingga nilai 50 disubsitusikan untuk nilai $\mathrm{y}$, dan akan didapat nilai $\mathrm{x}$ sebagai nilai $\mathrm{IC}_{50}$.

\section{Uji fitokimia}

Setiap perlakuan uji fitokimia mula-mula menimbang ekstrak kasar daun sebanyak $5 \mathrm{mg}$ gram, kemudian dilarutkan dengan tiga pelarut berbeda (metanol/etil asetat/n-heksan) sebanyak $5 \mathrm{ml}$ di dalam beaker glass [5].

\section{Perlakuan uji fitokimia}

Uji fitokimia dilakukan dengan metode kualitatif dengan tes perubahan warna dan kuantitatif menggunakan spektrofotometer UV-Vis pada panjang gelombang $517 \mathrm{~nm}$.

\section{a) Uji Senyawa Alkaloid}

Larutan sampel ditambahkkan sebanyak $1 \mathrm{ml}$ pereaksi dragendrof, amati perubahannya. Bila terbentuk warna jingga sampai merah coklat menunjukkan adanya senyawa alkaloid. Jika didapat hasil positif maka dilanjutkan dengan uji kuantitatif.

\section{b) Uji senyawa flavonoid}

Larutan sampel yang telah disiapkan ditambahkkan sebanyak $1 \mathrm{ml} \mathrm{HCl}$ pekat, kemudian ditambahkan 0,20 gram bubuk $\mathrm{Mg}$. Bila terbentuk warna kuning, jingga atau merah tua (magenta) menunjukkan adanya senyawa flavonoid. Jika didapat hasil positif maka dilanjutkan dengan uji kuantitatif.

\section{c) Uji senyawa saponin}

Larutan sampel yang telah disiapkan dimasukkan ke dalam botol vial, ditambahkan $1 \mathrm{ml}$ air panas, kemudian dikocok selama 15 menit, lalu ditambahkan $1 \mathrm{ml} \mathrm{HCl} 2 \mathrm{~N}$. Hasil positif ditunjukkan dengan terbentuknya buih putih stabil.

\section{d) Uji senyawa tanin}

Larutan sampel yang telah disiapkan ditambahkkan sebanyak $1 \mathrm{ml}$ larutan $\mathrm{FeCl}_{3}$ $1 \%$, kemudian amati perubahannya. Bila terbentuk warna biru atau hijau kehitaman mengindikasikan adanya senyawa tanin. Jika didapat hasil positif maka dilanjutkan dengan uji kuantitatif.

\section{HASIL DAN PEMBAHASAN}

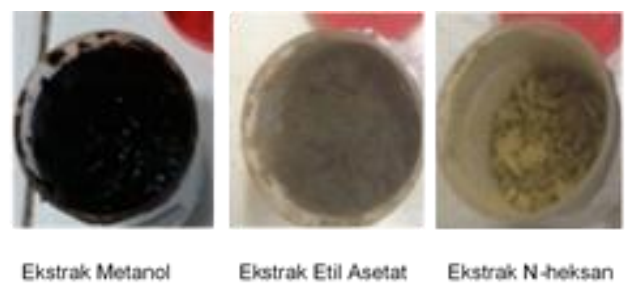

Gambar 2. Hasil Ekstrak Daun R.mucronata

Hasil ekstraksi pada sampel dengan menggunakan pelarut akan menghasilkan rendemen ekstrak yang berfungsi untuk mengetahui nilai komponen senyawa kimia aktif yang terkandung di dalam sampel. Rendemen ekstrak dihitung berdasarkan perbandingan berat akhir (berat ekstrak yang dihasilkan) dengan berat awal (berat sampel yang digunakan) dikalikan $100 \%$ [6]. ekstrak kasar methanol memiliki nilai rendemen 
$35,30 \%$ (70,66 g), ekstrak kasar etil asetat $13,60 \%$ (13,62 g), dan ekstrak kasar n-heksan $1,2 \%(1,20 \mathrm{~g})$ (Gambar 2).

\section{Uji fitokimia}

Tabel 1. Hasil Uji Fitokimia Ekstrak Metanol Daun $R$. mucronata

\begin{tabular}{|c|c|c|c|c|}
\hline \multirow[b]{2}{*}{ No } & \multirow{2}{*}{$\begin{array}{l}\text { Senya- } \\
\text { wa } \\
\text { Kimia } \\
\text { Aktif }\end{array}$} & \multicolumn{2}{|c|}{ Daun } & \multirow[b]{2}{*}{$\begin{array}{l}\text { Karakteri- } \\
\text { stik }\end{array}$} \\
\hline & & $\begin{array}{l}\text { Kuali- } \\
\text { tatif }\end{array}$ & $\begin{array}{l}\text { Kuant- } \\
\text { itatif } \\
\text { (ppm) }\end{array}$ & \\
\hline 1 & $\begin{array}{l}\text { Alka- } \\
\text { loid }\end{array}$ & Ada & 123,77 & $\begin{array}{l}\text { Terbentuk } \\
\text { warna } \\
\text { jingga } \\
\text { sampai } \\
\text { merah } \\
\text { coklat }\end{array}$ \\
\hline 2 & $\begin{array}{l}\text { Flavo- } \\
\text { noid }\end{array}$ & Ada & 1195,00 & $\begin{array}{l}\text { Terbentuk } \\
\text { warna } \\
\text { kuning, } \\
\text { jingga atau } \\
\text { merah }\end{array}$ \\
\hline 3 & $\begin{array}{l}\text { Sapo- } \\
\text { nin }\end{array}$ & $\begin{array}{l}\text { Tidak } \\
\text { ada }\end{array}$ & - & $\begin{array}{l}\text { Terbentukny } \\
\text { a busa }\end{array}$ \\
\hline 4 & Tanin & Ada & 576,70 & $\begin{array}{l}\text { Terbentuk } \\
\text { warna hijau } \\
\text { atau biru } \\
\text { kehitaman }\end{array}$ \\
\hline
\end{tabular}

*pengenceran 1:8

Tabel 2. Hasil Uji Fitokimia Ekstrak Etil Asetat Daun R. mucronata

\begin{tabular}{|c|c|c|c|c|}
\hline \multirow[b]{2}{*}{ No } & \multirow{2}{*}{$\begin{array}{l}\text { Senya- } \\
\text { wa } \\
\text { Kimia } \\
\text { Aktif }\end{array}$} & \multicolumn{2}{|c|}{ Daun } & \multirow[b]{2}{*}{$\begin{array}{l}\text { Karak- } \\
\text { teristik }\end{array}$} \\
\hline & & $\begin{array}{l}\text { Kualit } \\
\text { atif }\end{array}$ & $\begin{array}{l}\text { Kuanti } \\
\text { tatif } \\
\text { (ppm) }\end{array}$ & \\
\hline 1 & $\begin{array}{l}\text { Alka- } \\
\text { loid }\end{array}$ & Ada & 44,91 & $\begin{array}{l}\text { Terbentuk } \\
\text { warna jingga } \\
\text { sampai merah } \\
\text { coklat }\end{array}$ \\
\hline 2 & $\begin{array}{l}\text { Flavo- } \\
\text { noid }\end{array}$ & $\begin{array}{l}\text { Tidak } \\
\text { ada }\end{array}$ & - & $\begin{array}{l}\text { Terbentuk } \\
\text { warna kuning, } \\
\text { jingga atau } \\
\text { merah }\end{array}$ \\
\hline 3 & $\begin{array}{l}\text { Sapon- } \\
\text { in }\end{array}$ & $\begin{array}{l}\text { Tidak } \\
\text { ada }\end{array}$ & - & $\begin{array}{l}\text { Terbentuknya } \\
\text { busa }\end{array}$ \\
\hline 4 & Tanin & Ada & 84,84 & $\begin{array}{l}\text { Terbentuk } \\
\text { warna hijau } \\
\text { atau biru } \\
\text { kehitaman }\end{array}$ \\
\hline
\end{tabular}

Hasil uji fitokimia terhadap senyawa metabolit sekunder ekstrak metanol daun R.mucronata menunjukkan adanya senyawa alkaloid, flavonoid dan tanin. Berikut tabel hasil uji fitokimia disajikan pada (Tabel 1,2 dan 3).

Tabel 3. Hasil Uji Fitokimi Ekstrak N-heksan Daun R. mucronata

\begin{tabular}{|c|c|c|c|c|}
\hline \multirow[b]{2}{*}{ No } & \multirow{2}{*}{$\begin{array}{l}\text { Senya- } \\
\text { wa } \\
\text { Kimia } \\
\text { Aktif }\end{array}$} & \multicolumn{2}{|l|}{ Daun } & \multirow[b]{2}{*}{$\begin{array}{l}\text { Karakteri- } \\
\text { stik }\end{array}$} \\
\hline & & $\begin{array}{l}\text { Kuali- } \\
\text { tatif }\end{array}$ & $\begin{array}{l}\text { Kuant- } \\
\text { itatif } \\
\text { (ppm) }\end{array}$ & \\
\hline 1 & $\begin{array}{l}\text { Alka- } \\
\text { loid }\end{array}$ & Ada & 41,49 & $\begin{array}{l}\text { Terbentuk } \\
\text { warna } \\
\text { jingga } \\
\text { sampai } \\
\text { merah } \\
\text { coklat }\end{array}$ \\
\hline 2 & $\begin{array}{l}\text { Flavo- } \\
\text { noid }\end{array}$ & $\begin{array}{l}\text { Tidak } \\
\text { ada }\end{array}$ & - & $\begin{array}{l}\text { Terbentuk } \\
\text { warna } \\
\text { kuning, } \\
\text { jingga atau } \\
\text { merah }\end{array}$ \\
\hline 3 & $\begin{array}{l}\text { Sapo- } \\
\text { nin }\end{array}$ & $\begin{array}{l}\text { Tidak } \\
\text { ada }\end{array}$ & - & $\begin{array}{l}\text { Terbentukny } \\
\text { a busa } \\
\text { Terbentuk }\end{array}$ \\
\hline 4 & Tanin & Ada & 67,30 & $\begin{array}{l}\text { warna hijau } \\
\text { atau biru } \\
\text { kehitaman }\end{array}$ \\
\hline
\end{tabular}

Berdasarkan penelitian ini hasil uji fitokimia kandungan senyawa ekstrak daun dari tiga pelarut berbeda mengandung senyawa alkaloid, flavonoid dan tanin dengan kandungan senyawa terbanyak terdapat pada ekstrak metanol daun.

\section{Uji aktivitas antioksidan}

Adanya aktivitas antioksidan ditandai dengan berubahnya warna larutan dari ungu menjadi kuning, dengan warna awal larutan DPPH adalah ungu gelap. Hasil pengujian aktivitas antioksidan ekstrak metanol daun $R$. mucronata menunjukkan perubahan warna kuning pada konsentrasi 62,50; 125; dan 250 ppm. Pada ekstrak etil asetat perubahan warna kuning terjadi pada konsentrasi 250 ppm, sedangkan pada ekstrak n-heksan hanya terja- 
Tabel 4. Nilai IC $_{50}$ dan Klasifikasi Sifat Antioksidan

Ekstrak Daun R. Mucronta

\begin{tabular}{|c|c|c|c|c|c|}
\hline Pelarut & $\begin{array}{l}\text { Konsentr } \\
\text { asi (ppm) }\end{array}$ & Absorbansi & $\%$ Inhibisi & $\mathrm{IC}_{50}(\mathrm{ppm})$ & $\begin{array}{l}\text { Sifat } \\
\text { Antioksidan }\end{array}$ \\
\hline \multirow{4}{*}{ Metanol } & 31,25 & 0,415 & 49,57 & \multirow{4}{*}{$-117,49$} & \multirow{4}{*}{ Tidak terdefinisi } \\
\hline & 62,5 & 0,092 & 88,85 & & \\
\hline & 125 & 0,077 & 90,68 & & \\
\hline & 250 & 0,081 & 90,19 & & \\
\hline \multirow{4}{*}{ Etil asetat } & 31,25 & 0,977 & $-18,77$ & \multirow{4}{*}{160,42} & \multirow{4}{*}{ Lemah } \\
\hline & 62,5 & 0,842 & $-2,35$ & & \\
\hline & 125 & 0,404 & 50,91 & & \\
\hline & 250 & 0,112 & 86,38 & & \\
\hline \multirow{4}{*}{ N-heksan } & 31,25 & 1,014 & $-31,46$ & \multirow{4}{*}{327,61} & \multirow{4}{*}{ Sangat Lemah } \\
\hline & 62,5 & 0,930 & $-31,25$ & & \\
\hline & 125 & 0,626 & $-16,21$ & & \\
\hline & 250 & 0,563 & 30,20 & & \\
\hline \multicolumn{2}{|c|}{ Blanko } & 0,822 & & & \\
\hline
\end{tabular}

-di pemudaran warna ungu pada semua konsentrasi. Pada kontrol positif vitamin C terjadi perubahan warna kuning pada semua konsentrasi yaitu 2 ppm, 4 ppm, 6 ppm, dan 8 ppm

Perhitungan nilai $\mathrm{IC}_{50}$ ekstrak metanol daun diperoleh dari persamaan regresi yaitu $117,498 \mu \mathrm{g} / \mathrm{ml}$; ekstrak etil asetat yaitu 160,417 $\mu \mathrm{g} / \mathrm{ml}$; ekstrak n-heksan 327,611 $\mu \mathrm{g} / \mathrm{ml}$. Ekstrak etil asetat dan n-heksan $R$. mucronata memiliki aktivitas antioksidan jauh lebih lemah dibanding dengan kontrol positif vitamin $\mathrm{C}$ dengan nilai $\mathrm{IC}_{50} 4,419 \mu \mathrm{g} / \mathrm{ml}$.

Hasil uji antioksidan menunjukkan bahwa ekstrak etil asetat dan n-heksan memiliki sifat antioksidan yang sangat lemah, sedangkan ekstrak methanol tidak terdefinisi (Tabel 4). Berbeda dengan hasil penelitian yang menunjukkan nilai $\mathrm{IC}_{50}$ ekstrak methanol daun R. mucronata sebesat 4,90 ppm dengan sifat antioksidan yang sangat kuat [6]. Hal tersebut diduga terjadi karena beberapa hal seperti metode dan jenis pelarut. Penggunaan metode dan pelarut dalam ekstraksi dapat mempengaruhi hasil ekstraksi [7]. Selain itu, perbandingan jumlah ekstrak kasar san larutan DPPH yang digunakan juga akan mempengaruhi hasil uji antioksidan. Kondisi alam asal sampel juga akan berpengaruh terhadap aktivitas biologis yang dimiliki sampel. Sampel yang berasal dari daerah ekstrem biasanya akan menghasilkan metabotil sekunder yang lebih banyak sehingga diduga akan memiliki aktivitas biologis yang lebih bagus.

Walaupun tidak terdefinisi dan tergolong sangat lemah, tetapi ekstrak metanol, etil asetat dan n-heksan daun $R$. mucronata memiliki potensi sebagai antioksidan karena di dalamnya terdapat beberapa senyawa antioksidan. Telah diketahui bahwa senyawa fenol seperti tanin pada tumbuhan mengandung sifat antioksidan [8].

\section{KESIMPULAN}

Hasil penelitian uji aktivitas antioksidan dapat disimpulkan bahwa ekstrak etil asetat dan n-heksan $R$. mucronata menunjukkan aktivitas antioksidan namun tergolong lemah dan sangat lemah pada konsentrasi $\mathrm{IC}_{50}$ sebesar 160,417 ppm dan 327,611 ppm.

Ekstrak daun $R$. mucronata mengandung senyawa alkaloid, flavonoid dan tanin. Hasil pengujian fitokimia secara kuantitatif mengandung sejumlah senyawa alkaloid, flavonoid dan tanin dari yang terbesar sampai terkecil secara berturut-turut yaitu ekstrak 
metanol sebesar 1895,47 ppm, etil asetat sebesar 129,75 ppm dan n-heksan sebesar $108,79 \mathrm{ppm}$.

\section{DAFTAR PUSTAKA}

[1] D. Tristantini, A. Ismawati, B. T. Pradana, J. G. Jonathan. "Pengujian Aktivitas Antioksidan Menggunakan Metode DPPH pada Daun Tanjung (Mimusops elengi L)". Prosiding Seminar Nasional Teknik Kimia "Kejuangan" Pengembangan Teknologi Kimia untuk Pengolahan Sumber Daya Alam Indonesia. 2016.

[2] O. I. Aruoma. "Free Radicals, Oxidative Stress, and Antioxidants in Human Health and Disease". JAOCS 75 (2): 199212. 1998.

[3] I. J. Putri, Fauziyah, dan Elfita. "Aktivitas Antioksidan Daun dan Biji Buah Nipah (Nypa fruticans) Asal Pesisir Banyuasin Sumatera Selatan Dengan Metode DPPH”. Maspari J. 5 (1): 16-21. 2013.
[4] H. Purnobasuki, H. "Tinjauan Perspektif Hutan Mangrove". Univ. Airlangga Press: Surabaya. 2005.

[5] Sapri, R. Pebrianti, dan M. Faizal. "Uji Aktivitas Antioksidan Ekstrak Metanol Tumbuhan Singgah Perempuan (Loranthus sp) dengan Metode DPPH (2,2-Difenil-1-Pikrilhidrazil)". Prosiding Seminar Nasional Kimia : 203-210. Akademi Farmasi dan BPOM Samarinda. 2013.

[6] W. T. Wahyuni, L. K. Darusman, dan N. K. Surya. "Potency of Rhizopora spp. Extracts as Antioxidant and Inhibitor of Acetylcholinesterase". Procedia Chemistry 16: 681-686. 2015.

[7] P. Moteriya, A. Dalsaniya, S. Chanda. "Antioxidant and Antimicrobial Activity of a Mangrove Plants Avicennia marina (Forsk.)". J. Coastal Life Medecine 3 (9): 713-717. 2015.

[8] E. Suryanto dan F. Wehantouw. "Aktivitas Penangkap Radikal Bebas dari Ekstrak Fenolik Daun Sukun (Artocarpus altilis F.)". Chemistry Program 2 (1) : 17. 2009. 